\title{
ERRATUM
}

\section{Determining the natural length of the current interglacial}

P. C. Tzedakis, J. E. T. Channell, D. A. Hodell, H. F. Kleiven and L. C. Skinner

Nature Geoscience http://dx.doi.org/10.1038/ngeo1358 (2012); published online 09 January 2012; corrected online 10 January 2012.

The PDF of this Letter originally appeared with the incorrect 'published online' date of 8 January 2012; the actual date it went live was 9 January 2012. The date is now correct on all versions of the Letter. 